\title{
Article
}

\section{Bridging the Undergraduate Curriculum Using an Integrated Course-Embedded Undergraduate Research Experience (ICURE)}

\author{
James E. Russell, ${ }^{*}$ Allison R. D'Costa, ${ }^{*}$ Clay Runck, ${ }^{*}$ David W. Barnes, ${ }^{*}$ \\ Alessandra L. Barrera, * Jennifer Hurst-Kennedy,* Elizabeth B. Sudduth,* \\ Erin L. Quinlan, ${ }^{*}$ Mark Schlueter, ${ }^{*}$ Liliya A. Iskhakova, ${ }^{\dagger}$ and Robert Haining*
}

\author{
*School of Science and Technology (Biology), Georgia Gwinnett College, Lawrenceville, GA 30043; ${ }^{\dagger}$ Department \\ of Medical Neurobiology, Hebrew University of Jerusalem, Jerusalem 9112102, Israel
}

Submitted September 24, 2014; Revised November 25, 2014; Accepted December 18, 2014

Monitoring Editor: Graham F. Hatfull

\begin{abstract}
The traditional undergraduate program of study incorporates a selection of classes that represent a broad spectrum of subdisciplines. Unfortunately, few curricula successfully integrate concepts in all subdisciplines, giving undergraduates the misconception that there is a lack of application or connectedness between class subjects. An integrated course-embedded research experience (ICURE) was initiated to redress this problem by bridging classes within one discipline in an effort to engage undergraduates in a long-term analysis of biodiversity. The approach was both inclusive and longitudinal: 1) the ICURE bridge brought students from different classes and levels of instruction together with faculty members in a research project with a common goal—chronicling the changing face of the local environment in biological terms; and 2) research data collected were maintained and supplemented each semester and year in an online biodiversity database. Analysis of content and attitudinal gains suggested the integrated research protocol increased student comprehension and confidence. Results are discussed in terms of future amendments to instructional design and potential research applications. Though this program was concentrated on one discipline, there is no reason to assume other disciplines could not take advantage of similar research connections.
\end{abstract}

\section{INTRODUCTION}

In 1998, the Boyer Commission report recommended that engaging students in research in introductory courses would increase students' interest in science, technology,

CBE Life Sci Educ March 2, 2015 14:ar4

DOI:10.1187/cbe.14-09-0151

J.E.R. was involved in the implementation and assessment of the curriculum described in the manuscript. No promotion of the curriculum described herein to the exclusion of other similar curricula should be construed.

Address correspondence to: James E. Russell (jrussell@ggc.edu).

(c) 2015 J. E. Russell et al. CBE-Life Sciences Education (c) 2015 The American Society for Cell Biology. This article is distributed by The American Society for Cell Biology under license from the author(s). It is available to the public under an Attribution-NoncommercialShare Alike 3.0 Unported Creative Commons License (http://creativecommons.org/licenses/by-nc-sa/3.0).

"ASCB ${ }^{\circledR}$ " and "The American Society for Cell Biology ${ }^{\circledR}$ " are registered trademarks of The American Society for Cell Biology. engineering, and mathematics (STEM)-related fields and that research skills and competencies could be developed in subsequent years so that graduating seniors would be able to easily transition into advanced jobs and careers (Boyer Commission on Educating Undergraduates in the Research University, 1998). Since then, a research experience has become a fundamental component of undergraduate education, and several quantitative and qualitative studies have demonstrated the many benefits of a research experience for students (Kardash, 2000; Lopatto, 2004, 2007; Seymour et al., 2004). Additionally, Russell et al. (2007) reaffirmed that introducing students to research opportunities early in their academic careers had the greatest benefit. Based on these assessments, the 2011 American Association for the Advancement of Science's Vision and Change in Undergraduate Biology Education report (AAAS, 2011) advocated a call to "introduce the scientific process to students early, and integrate it into all undergraduate biology courses" (page xiv).

The most widely used approach to undergraduate research has been the "apprenticeship" model (Wei and Woodin, 2011), 
in which a student conducts an independent research project in a faculty member's laboratory across the academic year and/or summer. These independent research experiences, mainly offered to juniors and seniors (who have already decided to become science majors and are often selected by faculty members), have provided enormous benefits, as mentioned in the studies cited earlier. These studies and the recent call from the Vision and Change report have increased the demand on colleges and universities to offer more ways for students to be exposed to research. Apprentice-style undergraduate research experiences (UREs) require research laboratory space and financial and faculty resources and are a burden on institutions that do not have research as a large part of their mission (Wei and Woodin, 2011). They might also exclude those students who might not have the funds or time to do research in the summer. In addition, the apprenticeship model might discourage underrepresented minorities from participating, because they are unfamiliar or uncomfortable with the idea of research (Wei and Woodin, 2011).

To accommodate the increasing demand for student research, science faculty members have found innovative ways to offer authentic research experiences to a broader population of students by integrating them into the course curriculum (Karukstis and Elgren, 2007; Healey and Jenkins, 2009). These course-based undergraduate research experiences (CUREs) target all students enrolled in a course. Research is conducted as part of the course, in the classroom and teaching labs.

In this paper, we describe a course-embedded research project that bridges undergraduate courses by integrating laboratory research experiences (ICURE). Traditionally, undergraduate programs of study incorporate a selection of courses in an attempt to provide a foundational understanding for any given academic discipline. These courses typically represent a broad spectrum of subdisciplines that can appear to be disconnected from one another, despite the inherent integrative nature of most academic disciplines. In the biological sciences curriculum, this disconnect is commonly observed among "organismal" and "cell" or "molecular" biology courses. The organismal courses are characterized as dealing primarily with higher orders of biological organization, beginning with the individual organism and including populations, communities, and ecosystems. The cell or molecular biology courses are characterized by the lower orders of biological organization and include everything from molecular genetics and biochemistry to cellular structure and function. A comprehensive understanding of biology, however, requires an integration of all levels of organization. With this in mind, we developed an integrative instructional design attempting to bridge the organismal-cell/molecular gap using genetic tools to address lower-order biological questions relevant in a higher-order ecological context.

Initially, a freshman introductory biology course for majors (Principles of Biology, POB, BIOL1108) and a sophomore-level cell biology (BIOL3400) course were used to integrate diagnostic techniques typically taught separately. The common research goal was the identification of insects on the Georgia Gwinnett College (GGC) campus. As explained in the Discussion section, this ICURE was later moved to involve integration between a junior-level Ecology course (BIOL3500) and the Cell Biology (BIOL3400) course. The long-term research goal for the initiation of this project was to obtain measurements of insect biodiversity in a rapidly changing environment, represented by the growing campus of the GGC, which was opened in August 2006 with 118 students and as of Fall 2014 enrolled 10,000 students. The primary educational goal was horizontal integration of two biology course laboratories focusing on a common laboratory outcome: the identification of insects. Pedagogical support for research-based course integration has been previously demonstrated in undergraduate medical programs in Sweden, where course integration resulted in improved understanding and retention of basic science principles (Brynhildsen et al., 2002; Dahle et al., 2002)

Insect identification was used to integrate course laboratories for several reasons. First, insects represent the vast majority of organismal biodiversity, a foundational concept in biology. Second, though methods used to evaluate insect biodiversity are well developed (Foottit and Adler, 2009), the methods used to identify insects are currently undergoing revision due to advances in molecular technology (Park et al., 2011). DNA bar coding is a relatively new molecular technique that uses DNA sequence data to identify insects and other organisms and has standardized protocols easily adapted to undergraduate laboratory courses (Hebert et al., 2003). Third, the act of insect identification allows students to apply alternative techniques for a common research goal, emphasizing the holistic nature of scientific research.

\section{METHODS AND PEDAGOGY}

\section{ICURE in POB}

The research experience was administered in one-semester blocks (Table 1) and began with students in POB collecting insects at predetermined sites on campus using Malaise traps (model 2875D; BioQuip Products, Rancho Dominguez, CA) charged with $95 \%$ ethanol used to maintain DNA integrity. For the Fall 2011 semester of POB, three sites, representing a transect across the GGC campus, were selected.

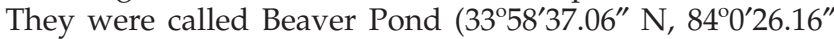
$\mathrm{W})$, Forest Island ( $\left.33^{\circ} 58^{\prime} 46.42^{\prime \prime} \mathrm{N}, 84^{\circ} 0^{\prime} 24.16^{\prime \prime} \mathrm{W}\right)$, and Building B (33 $\left.58^{\prime} 54.79^{\prime \prime} \mathrm{N}, 84^{\circ} 00^{\prime} 23.22^{\prime \prime} \mathrm{W}\right)$. These locations had been previously used for field laboratory exercises in $\mathrm{POB}$ and Ecology. In subsequent semesters, the sampling sites were chosen to represent various levels of disturbance based upon distance from impermeable surface roads. GGC sites 1, formally "Building B" (33 $\left.58^{\prime} 54.79^{\prime \prime} \mathrm{N}, 8^{\circ} 00^{\prime} 23.22^{\prime \prime} \mathrm{W}\right)$ and $4\left(33^{\circ} 58^{\prime} 56.16^{\prime \prime} \mathrm{N}, 8^{\circ} 00^{\prime} 21.33^{\prime \prime} \mathrm{W}\right)$ were considered high-disturbance sites, as both were within $30 \mathrm{~m}$ of impermeable surface roads. GGC sites $2\left(33^{\circ} 58^{\prime} 58.43^{\prime \prime} \mathrm{N}, 84^{\circ} 00^{\prime} 21.33^{\prime \prime} \mathrm{W}\right)$ and $3\left(33^{\circ} 59^{\prime} 03.87^{\prime \prime} \mathrm{N}, 84^{\circ} 00^{\prime} 20.37^{\prime \prime} \mathrm{W}\right)$ were considered relatively low-disturbance sites, because they were more than $50 \mathrm{~m}$ from impermeable surface roads. All sampling sites were located in or adjacent to deciduous woodland and firstor second-order headwater streams. GGC site 1 was located on a forest trail $30 \mathrm{~m}$ from a paved road and $\sim 30 \mathrm{~m}$ from an electrical power line easement. GGC site 2 was located on the edge of the power line easement and the previously mentioned forest. GGC site 3 was located beside a headwater stream in an area of deciduous woodland. GGC site 4 was located upstream of GGC site 3 in an early successional forest edge clearing. 
Table 1. Timeline for completion of the biodiversity/DNA bar-coding collaborative ICURE over a semester

\begin{tabular}{|c|c|c|}
\hline Week & POB/Ecology & Cell Biology \\
\hline 1 & Introduction to biostatistics & \\
\hline 2 & $\begin{array}{l}\text { Set malaise traps; introduction to } \\
\text { entomology }\end{array}$ & \\
\hline 3 & $\begin{array}{l}\text { Sort collected insects to the order } \\
\text { level; photograph insect samples }\end{array}$ & \\
\hline 4 & Sort insects to morphospecies & \\
\hline 5 & $\begin{array}{l}\text { Hand over insects to Cell Biology; } \\
\text { determine biodiversity index } \\
\text { values; wiki page construction }\end{array}$ & $\begin{array}{l}\text { DNA extraction from } \\
\text { insect samples }\end{array}$ \\
\hline 6 & & $\begin{array}{l}\text { PCR amplification of } \\
\text { CO1 gene region }\end{array}$ \\
\hline 7 & & $\begin{array}{l}\text { Gel electrophoresis, } \\
\text { troubleshoot; re- } \\
\text { PCR }\end{array}$ \\
\hline 8 & & $\begin{array}{l}\text { Gel electrophoresis, } \\
\text { troubleshoot; re- } \\
\text { PCR }\end{array}$ \\
\hline 9 & & $\begin{array}{l}\text { Gel electrophoresis, } \\
\text { PCR product } \\
\text { clean-up; sequence } \\
\text { preparation }\end{array}$ \\
\hline 10 & & $\begin{array}{l}\text { Introduction to bioin- } \\
\text { formatics-BLAST }\end{array}$ \\
\hline 11 & $\begin{array}{l}\text { Data transfer between collaborating } \\
\text { laboratories }\end{array}$ & $\begin{array}{l}\text { Molecular identifica- } \\
\text { tion of insects }\end{array}$ \\
\hline 12 & $\begin{array}{l}\text { Students collaborate to complete } \\
\text { wiki page on insect identification }\end{array}$ & \\
\hline
\end{tabular}

The insects were initially sorted by students into their respective order using dichotomous keys (Triplehorn and Johnson, 2005) and were eventually sorted to morphospecies. A morphospecies is a recognizable taxonomic unit (Derraik et al., 2009) and, in practice, often resulted in students defining unique species based on distinguishing morphological features. Selected insects were chosen for molecular bar code identification, and photographs were taken using trinocular dissecting microscopes fitted with Canon G12 digital cameras. Photographic records and preliminary taxonomic and natural history information were documented on student/species-specific wiki pages, along with biodiversity index values determined for each sample site (see biodiversity/bar-coding wiki pages: http://wiki.ggc .edu/wiki/The_DNA_Barcoding_Project). Each insect sample was uniquely numerically identified and recorded in an Excel spreadsheet for accurate tracking between course laboratories and students.

While experimental course sections worked on the biodiversity project, control sections in POB did traditional laboratory exercises associated with the scientific method, classification using preserved organisms, and one guided-research project involving plant growth.

\section{ICURE in Ecology}

In addition to the above methods, Ecology students determined biodiversity index values using the Shannon-Wiener function: $H^{\prime}=-\sum \mathrm{p}_{i}\left(\ln \mathrm{p}_{i}\right)$, where $\mathrm{p}_{i}$ represents the proportion of a morphospecies in a given community (sampling site). Students worked in teams of three to five students per site and were tasked with developing Excel functions to determine biodiversity index values. Ecology students compared biodiversity index values between sample sites and semesters in the Fall 2012 and Spring 2013 semesters using a modified $t$ test of diversity indices (Nangendo et al., 2002). Owing to discrepancies in data collection between Ecology sections for GGC sites 2 and 3 in the Fall 2012 semester, $t$ tests involving these sites were omitted.

When lab times coincided, the POB/Ecology students personally transferred their insect samples to their corresponding Cell Biology student collaborators. During the meeting of $\sim 15 \mathrm{~min}$, students shared taxonomic and natural history information obtained regarding the transferred insects and exchanged contact information. While experimental course sections worked on the biodiversity project, control sections in Ecology did a series of small research projects, such as leaf litter decomposition analysis, which involved data collection and statistical analysis of decomposition rates.

\section{ICURE in Cell Biology}

Cell Biology students worked independently to DNA bar code an individual insect (Table 1). A DNA bar code is a short DNA sequence used to distinguish species. A typical DNA bar-coding protocol involved DNA extraction followed by polymerase chain reaction (PCR) amplification of the bar-coding gene CO1 (cytochrome oxidase subunit 1, a mitochondrial gene), gel electrophoresis to determine the correct size of the PCR product, cleaning and sequencing of the PCR product, and, finally, bioinformatic analysis of the sequence to determine whether it matched other known insect sequences in GenBank or the International Barcode of Life databases (http:/ / blast.ncbi.nlm.nih.gov/Blast.cgi; www.boldsystems .org). Students were introduced to DNA bar coding through literature reviews, animations, and short videos, and they learned how molecular bar coding supplements traditional taxonomic methods in species identification.

Students used basic dissection tools and sterile techniques to obtain $\sim 2 \mathrm{~mm}$ of insect abdominal tissue for DNA extraction, or they used the entire insect, if it was very small. DNA was extracted using a Qiagen DNeasy Blood \& Tissue kit (Qiagen, Valencia, CA) or a proteinase K/5\% Chelex resin (Chelex 100 Resin, \#142-1253; Bio-Rad, Richmond, CA) method of DNA extraction (Walsh et al., 1991). Students were tested on their understanding of the use of each reagent in the extraction process and were required to draw a flowchart detailing the process before they began DNA extraction. Before beginning their PCR experiments, students were taught basic concepts associated with gene amplification by PCR, including the breaking and reformation of hydrogen bonds during DNA denaturation/renaturation, complementary bonding between primers and template DNA, the location of primers annealing relative to the amplicon, and the direction in which Taq DNA polymerase extends the primers. Again, students were responsible for knowing the purpose of each reagent in the PCR. To reinforce concepts, students completed a worksheet detailing rules for optimal primer design (length, GC content, melting temperature [Tm], self-complementarity, and 3 '-end complementarity). Students conducted at least three PCRs to amplify CO1: one using the extracted insect DNA, another using template DNA known to contain the CO1 sequence (positive control), and, finally, a reaction that contained water instead of template DNA 
(negative control). The following reagents were used for each 30- $\mu$ PCR: $2 \mu \mathrm{l}$ of template DNA, $0.5 \mu \mathrm{l}$ each of forward (LCO; 5'GGTCAACAAATCATAAAGATATTGG3') and reverse (HCO; 5'TAAACTTCAGGGTGACCAAAAAATCA3') primers $\left(10 \mu \mathrm{M}\right.$; Folmer et al., 1994), $5 \mu \mathrm{l}$ buffer with $\mathrm{Mg}^{2+}$, $2 \mu \mathrm{l}$ dNTPs, and $0.5 \mu \mathrm{l} \mathrm{Taq}$ polymerase (\#50-443-969; Fisher, Takara). The CO1 gene was amplified using a standard 35-cycle PCR protocol with a $54^{\circ} \mathrm{C}$ annealing temperature. The PCR products were resolved on $1 \%$ agarose gels along with a 100-base pair ladder (\#N3232L; New England Biolabs). Students were instructed on the basics of gel electrophoresis, such as the use of buffers to conduct electricity, DNA migration through the gel matrix, and the proper use of gel electrophoresis apparatuses. Moreover, student groups were responsible for calculating the proper amounts of each reagent needed and for preparing all of their own buffers and gels.

After acquiring images of their gels, student groups presented their data to the class; this was followed by a group discussion on ways to optimize their PCR results, providing the students with an opportunity to learn experimental troubleshooting. After this initial attempt, students had two more opportunities to repeat their PCRs (Table 1). Common modifications made to PCR experiments 2 and 3 included altering the amount of template DNA and/or varying the annealing temperature. Approximately $40 \%$ of the students got a PCR product that was subsequently "cleaned" using Exosapit (\#AF78200200; Affymetrix, Fisher) and then sent with forward and reverse primers for twofold coverage sequencing at the Georgia Genomics Facility at the University of Georgia, Athens (http:/ / dna.uga.edu).

Next, students were introduced to basic bioinformatics and taught to use BLAST (Basic Local Alignment Search Tool) and FinchTV, a free sequence analysis software (FinchTV 1.4.0; Geospiza, www.geospiza.com/finchTV), while testing known CO1 sequences for matches in GenBank and the International Barcode of Life databases. This exercise was repeated when the insect sequences arrived. Approximately $30 \%$ of the students obtained readable sequences.

Finally, DNA bar-code sequences and the molecular identification numbers of the sample insects, usually at the species level, were shared with POB/Ecology students and uploaded to the wiki page. Students compared morphological and molecular species-identification techniques and updated the biodiversity/bar-coding wiki pages with consensus species identifications.

While experimental course sections worked on the bar-coding project, control sections in Cell Biology were being exposed to a different, pre-existing research experience in which they had to design experiments to study the effect of UV radiation on yeast survival. PCR techniques were taught in both experimental and control sections, with a specific focus on the cytochrome oxidase 1 (CO1) gene region in the experimental sections.

\section{Assessment Methods}

The effect of the ICURE on student learning (content), confidence in their ability to do science (research skills and competencies), and attitudes toward science was assessed using pre- and postexposure tests, quizzes, and surveys. Experimental integration of the course laboratories covered the Fall 2011 through Fall 2013 semesters. A total of 416 students were assessed for content gains and attitudinal changes in seven control and 20 experimental course sections taught by nine full-time faculty members (see Results for a breakdown of the number of students per course). Pre- and postcourse assessment surveys were administered for all experimental and control sections for content and attitudinal gains.

Content and Skills. Assessment questions for POB students covered taxonomy, field sampling methods, and classification (Supplemental Material 1); assessment questions for Ecology students covered taxonomy, ecology, and biodiversity methodology (Supplemental Material 2); and assessment questions for Cell Biology students focused on theory, concepts, and methodology related to DNA isolation, PCR, and DNA sequence analysis (Supplemental Material 3). Scores on content assessment exams were combined for all sections and years for each course, and mean post-pre learning gains were compared with a two-tailed $t$ test assuming unequal variances $(\alpha=0.05)$. All content knowledge percentage gains are reported as means $\pm 1 \mathrm{SE}$.

Attitudes. For the first semester, Fall 2011, the ICURE analysis survey (Lopatto, 2007) was administered for learning and attitudinal gains. Thereafter, a voluntary anonymous survey developed specifically for the GGC 4-yr STEM URE was administered for attitudinal gains (Supplemental Material 4). Attitudinal data for POB and Ecology were combined due to overlapping curricula and low postcourse sample size for POB attitudinal data. A two-tailed $t$ test (assuming unequal variance, $\alpha=0.05$ ) was used to compare pre- and postcourse assessment scores. Ordinal attitudinal data were numerically coded in the following manner for statistical analysis: strongly disagree $=4$, disagree $=3$, agree $=2$, and strongly agree $=$ 1. Mean values for ordinal attitudinal data were graphed by coding the data in the following manner: strongly disagree = -2 , disagree $=-1$, agree $=1$, and strongly agree $=2$ to graphically represent positive or negative changes in agreement with the attitudinal statements.

\section{RESULTS}

We have described an ICURE that bridged two levels of undergraduate courses and had students collaborate on a project that investigated campus biodiversity. The effectiveness of this ICURE was assessed for content and attitudinal gains across five semesters. The results of assessments for the ICURE, initially a collaboration between POB and Cell Biology courses in Fall 2011 and Spring 2012 (two semesters) and later a collaboration between Ecology and Cell Biology in Fall 2012-Fall 2013 (three semesters) are described in the following sections.

\section{Content Assessment}

POB. A total of 72 students (48 in experimental sections, 24 in control sections) in seven sections were assessed. The experimental sections showed significantly greater gains in average pre-post content assessment exam scores when compared with control sections $(t=2.62, p<0.013)$ : scores showed gains of 15.8 percentage points for experimental sections and 6.3 percentage points for control sections (Figure 1). 


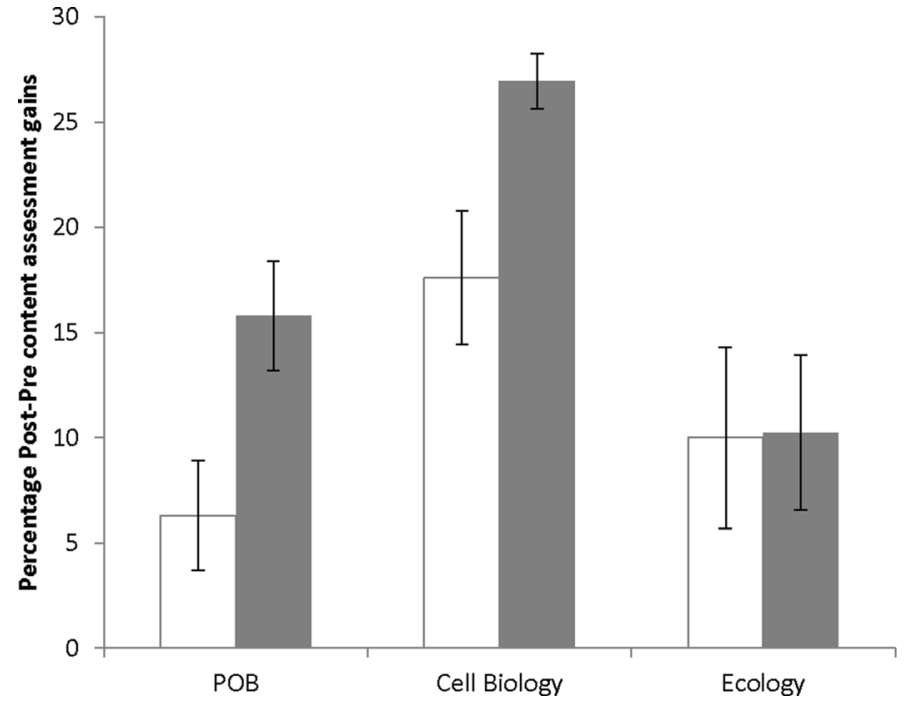

Ecology. A total of 46 students were assessed (36 in experimental sections, 10 in a control section) in four sections across the Fall 2012 and Spring 2013 semesters. Average pre-post content assessment exam scores showed gains of 10.3 percentage points for experimental sections and 10.0 percentage points for one control section (Figure 1). The experimental sections showed no significant gain when compared with the control section $(t=0.05, p>0.963)$.

Cell Biology. A total of 298 students were assessed (263 in experimental sections, 35 in control sections) in 16 sections from the Fall 2011 through Fall 2013 semesters. Average prepost content assessment exams scores showed gains of 26.9 percentage points for experimental sections and 17.6 percentage points for control sections (Figure 1). The experimental sections showed significantly greater gains when compared with control sections $(t=2.72, p<0.011)$. $\square$ Control

Experimental

Figure 1. Average percent gains $( \pm 1 \mathrm{SE})$ in prepost content assessment scores for students participating in the biodiversity/DNA bar-coding instructional design. POB data are for the Fall 2011-Spring 2012 semesters. Cell Biology data are for the Fall 2011-Fall 2013 semesters. Ecology data are from the Fall 2012-Spring 2013 semesters.

\section{Attitudinal Assessment}

CURE survey (Lopatto, 2007) analysis during the first semester (Fall 2011) of the integrated research experience supported the findings of the attitudinal assessments with above national average gains in experimental sections for "understanding science" and "understanding the research process." Below national average values for these two learning gains were observed in the control sections.

Analysis of data for attitudinal questions (see Methods and Supplemental Material 4) regarding the biodiversity portion of the ICURE came from a pooled POB and Ecology course data set. Positive pre-post changes in agreement with all attitudinal statements were observed for experimental sections; negative changes were observed for all statements in control sections (Figure 2). However, statistically significant differences between pre- and postassessment scores were only observed in the experimental section for the statements

\section{$\square$ Control $\square$ Experimental}

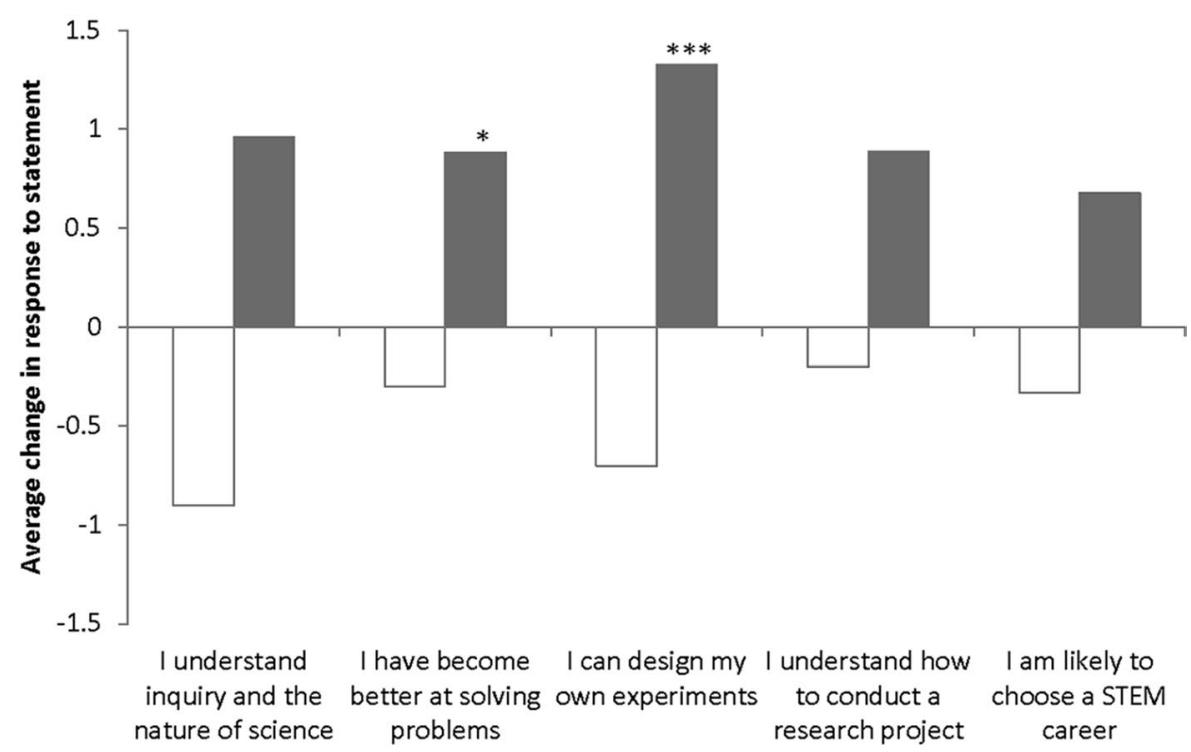

Figure 2. Assessment results for preto postcourse changes in attitudinal questions for Ecology and POB. Positive and negative values represent changes in agreement with statement ${ }^{*}, p<0.05$; $* * *, p<0.001)$. 


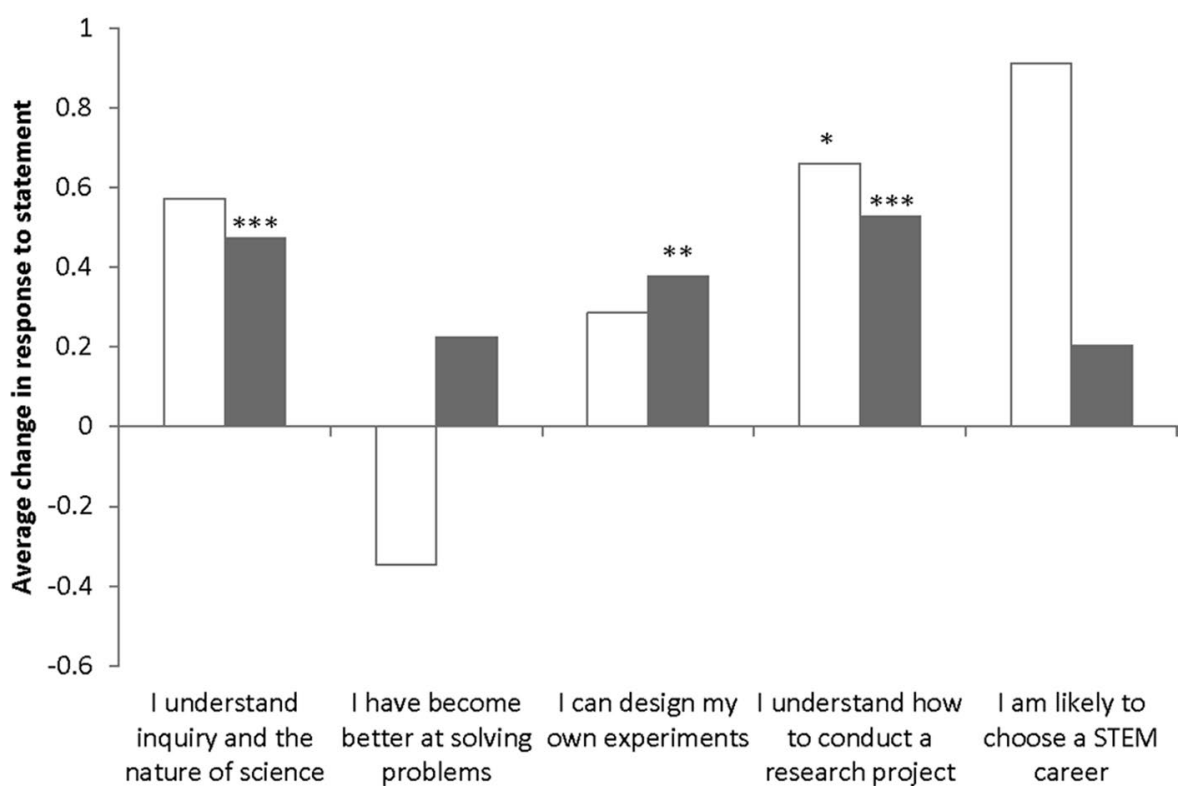

Figure 3. Assessment results for pre- to postcourse changes in attitudinal questions for Cell Biology. Positive and negative values represent changes in agreement with statement $\left({ }^{*}, p<0.05 ; * *, p<\right.$ $0.01 ; * * *, p<0.001)$.
"I have become better at overcoming obstacles and solving problems" and "I can design and carry out my own experiments or projects."

Positive pre-post changes in agreement with all attitudinal statements were observed in all experimental and control sections of Cell Biology, except for the statement "I have become better at overcoming obstacles and solving problems" in the control section (Figure 3). Significant differences between pre- and postassessment scores were found in both experimental and control sections for the statement "I understand how to conduct a research project" and for the experimental sections only for the statements "I can design and carry out my own experiments or projects" and "I understand inquiry and the nature of scientific investigation."

\section{Biodiversity Estimates and Database Construction}

The Fall 2011 semester was devoted to optimizing insect collection and preservation techniques, and no biodiversity estimates were taken. Before standardization of biodiversity sample sites, measurements were taken for two sample sites on the GGC campus in the Spring 2012 semester. Those sites were referred to as the Beaver Pond and the Forest Island and had Shannon-Wiener $\left(\mathrm{H}^{\prime}\right)$ biodiversity estimate values of 2.75 and 3.30, respectively. A total of 85 arthropod species pages were added to the GGC biodiversity / DNA bar-coding wiki covering 13 orders. No DNA database information was added to the wiki in the Spring 2012 semester. In the Fall 2012 semester, Shannon-Wiener biodiversity indices were calculated for four locations on the GGC campus, ranging from a low value of 1.58 to a high of 3.69. In the Spring 2013 semester, $\mathrm{H}^{\prime}$ values ranged from a low of 2.36 to a high of 3.95. In the Fall 2013 semester, $\mathrm{H}^{\prime}$ values ranged from a low of 1.75 to a high of 3.23 (Table 2). Significant differences were observed between the Fall 2012 and Spring 2013 semesters for GGC sites $1(t=5.99, p<0.001)$ and $4(t=11.79, p<0.001)$, with lower biodiversity values for both sites in 2013. In the Spring
2013 semester, GGC site 3 was significantly more diverse for arthropod fauna than GGC site $2(t=3.21, p<0.005)$, which was significantly more diverse than GGC sites $1(t=4.92, p<$ $0.001)$ and $4(t=8.86, p<0.001)$. GGC sites 1 and 4 were not statistically different in either semester (Table 2).

In the Fall 2012 semester, a total of 144 arthropod specimen pages were added to the GGC biodiversity/DNA bar-coding wiki, covering 11 arthropod orders. DNA bar-code (cytochrome oxidase subunit 1 [CO1]) data were collected and annotated on the wiki pages for 24 of the 144 specimens $(17 \%)$. In the Spring 2013 semester, a total of 130 arthropod specimen pages were added to the GGC biodiversity/DNA bar-coding wiki, covering 12 arthropod orders. DNA bar-code data were collected and annotated on the wiki pages for 64 out of the 130 specimens (49\%). In the Fall 2013 semester, a total of 112 arthropod specimen pages were added to the GGC biodiversity/DNA bar-coding wiki, covering nine arthropod orders. DNA bar-code data were collected and annotated on

Table 2. Shannon-Wiener biodiversity index values $\left(\mathrm{H}^{\prime}\right)$ for four arthropod sampling sites (GGC1-4) on the campus of GGC collected by students in the Fall 2012, Spring 2013, and Fall 2013 semesters of Ecology

\begin{tabular}{lcccc}
\hline & GGC 1 & GGC 2 & GGC 3 & GGC 4 \\
\hline Fall 2012 & $3.59^{\mathrm{b}}$ & 1.58 & 1.99 & $3.69^{\mathrm{b}}$ \\
Spring 2013 & $2.83^{\mathrm{c}}$ & $3.57^{\mathrm{b}}$ & $3.95^{\mathrm{a}}$ & $2.36^{\mathrm{c}}$ \\
Fall 2013 & 1.91 & 3.23 & 3.14 & 1.75
\end{tabular}

GGC sites 1 and 4 experienced increased disturbance over the course of the ICURE. The sample sites analyzed for significant differences in biodiversity $(p<0.008)$ are indicated by superscripts; significant differences are indicated by different superscripts. Not all samples in all years were statistically analyzed (see Results). 
Table 3. Database information gathered and posted on the GGC biodiversity/DNA bar-coding wiki (http:/ / wiki.ggc.edu/wiki/ The_DNA_Barcoding_Project) by undergraduates in the Fall 2012, Spring 2013, and Fall 2013 semesters $^{\mathrm{a}}$

\begin{tabular}{lccc}
\hline \multicolumn{1}{c}{ Semester } & Insect orders & $\begin{array}{c}\text { Number of } \\
\text { specimens }\end{array}$ & $\begin{array}{c}\text { Number of DNA } \\
\text { sequences }\end{array}$ \\
\hline Fall 2012 & 11 & 144 & 24 \\
Spring 2013 & 12 & 130 & 64 \\
Fall 2013 & 9 & 112 & 23 \\
Total $^{b}$ & 15 & 386 & 111 \\
\hline
\end{tabular}

${ }^{\mathrm{a}}$ Insect orders and specimens were collected by students in Ecology (BIOL3500) laboratory classes; DNA sequence information was generated by students in Cell Biology (BIOL3400) laboratories. Students from both courses participated in wiki page construction.

${ }^{\mathrm{b}}$ Total insect order values represent the total number of unique orders submitted to the wiki.

wiki pages for 23 out of the 112 specimens (21\%). A total of 386 specimen wiki pages were created, 111 of which contain DNA bar-coding data (29\%), for the Fall 2012-Fall 2013 semesters (Table 3).

\section{DISCUSSION}

We developed a novel ICURE that integrated distinct biology course laboratories by focusing on common research goal: insect identification. Our intention was to enhance the research experience by emphasizing the integrative nature of scientific discovery and investigation. By using two methods of insect identification, students could compare and contrast alternative approaches to a single common research goal. Each student was considered a student scientist, working toward a long-term research goal: studying the effects of urbanization on insect populations on our campus. Bridging the research experience over two courses offered in different years of the biology major enabled students to learn and build on skills addressing a common question and see continuity in the research process. Students in freshman POB participated in the organismal biology-focused part of the research experience and gained field experience and taxonomic skills in the context of insect identification. When they moved to sophomore-level Cell Biology, they were able to take part in the complementary cell/molecular component of the research experience and learned molecular biological and problem-solving skills involved in DNA bar coding. In the junior-level Ecology class, students participated in the long-term research goal by measuring biodiversity across time and space, using the scientific tools of statistical analysis and hypothesis testing. This integration of the undergraduate curriculum allowed students to realize that a question can be answered using different approaches and that research requires good collaboration. This experience provided the opportunity for students in their early years of matriculation to do authentic research, be exposed to the nature of science, and build on research skills to prepare them for advanced independent research in their junior/senior years.

After the first year of this ICURE (Fall 2011-Spring 2012), it was decided that students in Ecology, a junior-level course, would gain more from this experience than students in POB. Ecology students are better prepared for field experiences, have taken a statistics course and are taught to calculate biodiversity indices, have some previous experience with arthropod identification (in POB, arthropod diversity is not introduced in lab until the last third of the semester), and, importantly, have attained better computer skills to produce a wiki page. Another challenge was faculty buy-in in the POB sections for this research experience. Many felt that traditional labs help acclimatize freshman students to a lab atmosphere and that a research experience required students to already have, or learn, too many new skills in a single semester. So, beginning in Fall 2012, the ICURE was moved to Ecology, which has a much lower student enrollment than POB (e.g., two sections of Ecology vs. 17 sections of POB). As mentioned in the Methods and Pedagogy section, these students began the ICURE in the same way as POB but did additional analyses on the insect data they collected. Again, at midsemester, they handed their insects over to the Cell Biology students to bar code.

\section{ICURE Content Assessment}

The pedagogical support for benefits obtained using ICURE integration methodology (Brynhildsen et al., 2002; Dahle et al., 2002; Shaffer et al., 2010) was confirmed in our experiment with content gains observed in all experimental sections. These gains were significantly greater than controls for two of the three courses participating.

Positive gains in Cell Biology should be weighted with the understanding that three of the 13 assessment questions could be considered as biased in favor of experimental sections. These three questions dealt specifically with CO1 and DNA bar coding, which were not covered in the control sections. Nonetheless, both control and experimental sections were exposed to PCR techniques, 10 of 13 assessment questions. A post hoc analysis of potential bias revealed there was no statistical difference in experimental results when the potentially biased questions were removed $(t=1.97, p>0.91)$.

The lack of significant differences in the Ecology experimental and control sections may have been a function of observed greater precourse scores among upper-level undergraduates (average Ecology pretest score $=62$ ); these students are typically in their third or fourth year of college instruction, compared with POB students, who are typically in their first year (average POB pretest score $=42 ; t=3.59, p<$ 0.003). Also, some of the Ecology students may have had exposure to biodiversity content in the first year of the ICURE when it was implemented in the lower-level POB course. Nevertheless, the postcourse scores did not differ between control and experimental sections. Some of this lack of difference may come from the nature of the control laboratory curriculum, which routinely integrates concepts with laboratory exercises in a manner similar to that being implemented in the ICURE.

\section{ICURE Attitudinal Assessment}

Positive changes in attitudinal assessment were observed for all statements in both biodiversity and DNA bar-coding portions of the implemented ICURE. These changes should be interpreted as a positive or negative gain in agreement with the statements. In other words, most of the scores 
were positive (meaning more students selected "agree" or "strongly agree" rather than "disagree" or "strongly disagree") for both pre- and postassessments. However, the number of occurrences of "agree" or "strongly agree" among the control sections declined, whereas they increased among the experimental sections. For the biodiversity section of this project, attitudes showed a clear directional pattern, though only significant for two statements: "I have become better at solving problems" and "I can design my own experiments." This may reflect the confidence of the instructors in the techniques implemented-insect trapping and identification and statistical analysis - and their ability to teach this content. These were all techniques previously used in POB and Ecology laboratories, for the most part. It is interesting, though, that the control sections showed no gains. Problem solving in Ecology/POB may have come from the troubleshooting students had to do when it came to identifying insects-they had to decide for themselves what insect group the sample belonged to and make a morphospecies determination, even though they really had no idea and no background in that area of expertise. Also, Ecology students were given a journal article to use for statistical analysis. They had to read the methods section and extract necessary statistical formulas. They were allowed to work in teams for this, and the class had to come up with consistent results. This forced them to resolve problematic discrepancies in statistical results. The syntax of the former statement "I have become ..." was clearly problematic, because precourse participants have no context upon which to evaluate themselves, and should be revised in future assessments, perhaps by using "I expect to become ..." in the preassessment question or by including "Not applicable" as a choice.

Significant positive attitudinal changes observed in Cell Biology for the statements "I understand inquiry and the nature of science" and "I understand how to conduct a research project" may have been a function of the open-ended nature of this ICURE and the instructional design. Cell Biology students often did not have prior information on the insect they were tasked with identifying. Therefore, they were conducting a discovery research project (discovering something unknown), the type of project students often associate with science and inquiry. Cell Biology instruction typically involved more than two troubleshooting steps associated with PCR gene amplification that may have influenced student attitudes regarding their understanding of how to conduct research. Positive attitudinal gains for all control sections may have been the result of a similar research experience in the control laboratories, during which students designed their own experiment, conducted research, and analyzed data involving exposure of yeast to UV irradiation. The differences between the magnitude and significance of the attitudinal changes in the experimental and control sections were likely a function of much lower sample size and statistical power in the control sections compared with the larger sample size and greater statistical power of the experimental sections.

Taken together, the experimental ICURE showed significant positive attitudinal changes for all areas assessed except for attitudes regarding the statement "I am likely to choose a STEM career." This contrasts with control sections that only showed significant positive attitudinal changes for one area associated with the understanding of how to conduct a research project in one course. The open-ended nature of the biodiversity/DNA bar-coding ICURE design along with experimental troubleshooting appears to have had positive attitudinal effects.

\section{ICURE Outcome: An Online Biodiversity Database}

The end result of the ICURE at GGC was a functioning database containing species identifications, genetic "bar-code" data, and estimates of biodiversity across time and space. Species identification was the research goal that linked the two courses using techniques derived in separate biological subdisciplines: taxonomy and molecular genetics. In practice, this often resulted in students in biodiversity laboratories establishing very general insect identifications (usually morphospecies resolved to insect order) that were later resolved to more specific identifications (genus or species) using genetic information obtained in the Cell Biology laboratories. Although there were clear misidentifications in the database, genetic support for some $28.8 \%$ of all specimens allowed students to confirm and clarify initial morphospecies determinations. The successes and failures of the DNA bar-coding portion of the research experience helped students evaluate the benefits of alternative research methods and the holistic nature of scientific investigation.

In one particularly fascinating instance, a student who correctly identified an insect to the order Coleoptera (beetles) received a genetic bar-code sequence from his partner in the Cell Biology laboratory that most closely matched a nematode. After initially assuming a mistake had been made, the student was able to use bioinformatic tools, made possible by the sequence information, to find the nematode sequence closely matched a species known to infect insects, a so-called entomopathic nematode, or insect-eating nematode. The conclusion drawn from this unexpected result was that the insect he had correctly identified as a beetle was likely infected with nematodes whose DNA was sequenced, drawing attention to unobserved biological complexity and species interactions-important ecological concepts. This was an example of unintended benefits gained by extending the research experience beyond the individual class laboratory.

Development of the online wiki has provided a media platform for student engagement with the broader scientific community. DNA sequence information allowed students to interact with the results of researchers from around the world via online genomic databases (National Center for Biotechnology Information and the International Barcode of Life Database). Exposure to genomic databases highlighted the potential benefit gained from such freely available resources and the potential for student contribution to the wider scientific community. A local high school student was recently awarded second place at the Georgia Science and Engineering Fair at the University of Georgia in Athens for her research on bacterial infection frequencies and coevolution of insects and bacteria using genetic data obtained from the online wiki.

Biodiversity estimates generated by students showed an interesting trend that may be a function of campus urbanization. The two designated high-disturbance sites showed a decrease in estimated biodiversity over the course of the ICURE. These sites were also the closest to major construction projects on the GGC campus associated with new road construction and athletic field development. The initial 
biodiversity values also showed lower biodiversity values in sites we designated "low disturbance" (though biodiversity values increased in subsequent semesters). Data-collection techniques were not as well-defined early in the research experience, and observed discrepancies in data collection involving species and individual counts may have played a role in the unexpectedly low biodiversity estimates for these sites. However, there may have been disturbances in these areas we were not able to observe, such as power line construction or clearing around the GGC site 2 area and/or stream flooding in the GGC site 3 area. Clearly, these results warrant further testing with continued monitoring and biodiversity analysis.

Although more data are clearly needed to address the impact of campus development, the biodiversity results provide baseline data from which future hypotheses can be tested. Not only has this provided faculty members with future research opportunities, it has also allowed students to see how science can address immediate local issues. The continuation of this database will allow students to participate in and bear witness to a cooperative and incremental scientific research experience. The database is an online research tool accessible to all and is currently being adapted to several other courses and research projects that address biological diversity.

\section{ICURE: Implementation Challenges}

Implementation of the biodiversity/DNA bar-coding ICURE requires cooperative faculty and staff resources. There were several logistical problems that had to be addressed early in the ICURE experimental process. Allowing students to interact personally with partners in other course laboratories requires coordinated scheduling of lab class periods. This is clearly impractical for many college course schedules. Fortunately, many students are proficient with social media resources and can navigate online communication effectively in place of personal contact. However, the challenge was to adopt a common communication platform for a novel ICURE, so students and faculty members could share information.

Negotiating the transition of material from POB/Ecology laboratories to Cell Biology laboratories also presented several problems. First, the insect material had to be handled, identified, photographed, and curated by students in the biodiversity portion of the ICURE without compromising DNA integrity. This was accomplished by requiring all insect sample handling be done in 95\% ethanol. Nevertheless, some samples may have been mishandled before transfer. Second, inaccurate sample labeling and record keeping caused confusion in the transfer process. Sample labels were often lost in the process of handling in the Cell Biology laboratories, and without accurate record keeping, data were hard to track between laboratories. A standardized spreadsheet with numerical identifiers for each sample was eventually created and shared among all laboratories for more accurate tracking of shared samples. Third, appropriate sample sizes had to be determined before transfer, because the goal was to have a Cell Biology partner for every POB/ Ecology student. Because class sizes were often different, appropriate measures had to be taken to assure partnership for all students. In practice, this often meant the biodiversity students would generate more than one sample for transfer and would have more than one partner, because the number of students in Cell Biology outnumbered those in POB/ Ecology courses. Ecology students were required to create multiple wiki pages, with each page having a single Cell Biology contributor.

The pilot for this ICURE was initially funded by an internal minigrant for the first year of implementation. The cost of disposable items (Taq, Qiagen DNA extraction kit, etc.) for DNA bar coding amounts to approximately $\$ 20$ per student, which is well within the course lab fee. Following year 1 , the costs were picked up by the laboratory budget of the School of Science and Technology, which sustains the cost for all sections (five to six) of Cell Biology per semester.

A less efficient but cost-effective DNA extraction protocol (proteinase K-Chelex) was implemented in the second academic year, resulting initially in fewer successful laboratory experiments. The nature of the experimental design for bar coding resulted in disproportionate influence of the initial DNA extraction step. If this initial step failed, all subsequent experiments had no possibility of succeeding. The inefficiency of the DNA extraction protocol and subsequent negative results may have led to disinterest, given the typical predetermined success of most laboratory course experiments, among students, resulting in lower postcourse content assessment scores.

Negative results in the DNA bar-coding laboratories were common, $71.2 \%$ of the insects were not sequenced. Because of the collaborative nature of this ICURE, students in both laboratories were impacted by a lack of data. For students in the Cell Biology laboratories, disinterest and frustration often resulted from an unfounded fear that their grade would be compromised by negative results. In other words, once they realized they were not going to able to contribute to the shared research goal, they felt the research process was a waste of time. However, experimental failure is an important part of the scientific process and was emphasized in the Cell Biology laboratories. Nevertheless, many students were used to laboratories in which results are guaranteed, so-called "cookbook" lab exercises, and were not pleased with their first experimental failure. Though the biodiversity laboratory students were not as negatively affected by negative DNA bar-coding results, they often expressed disappointment with the lack of genetic support for their morphospecies designations. A suggestion for improving the odds for success in bar coding would be to have students extract DNA from various parts of the insects, instead of just the abdomen (Methods and Pedagogy).

Lab preparation for five to six lab sections of Cell Biology was not an easy task. Even though each group of four students managed its own freezer box, reagents had to be dispensed on ice, labeled, and managed. This was done by student lab workers under the supervision of faculty members. Additional tubes had to be managed following the two or three rounds of PCR with various controls. Often, students did not realize the importance of proper labeling of tubes or diligent note taking to determine the contents of each tube. The purchase of $\mathrm{a}-20^{\circ} \mathrm{C}$ freezer placed in the lab eased some problems.

This novel ICURE could not have been possible without the excellent collaboration between all the faculty authors on this paper. Each one managed some aspect of the lab 
prep, several contributed ideas for worksheets to help students understand concepts, and all faculty members were responsible for conducting pre-post assessments in their courses.

\section{ACKNOWLEDGMENTS}

This ICURE was initiated with the assistance of funding by a competitive minigrant from the School of Science and Technology at GGC with funds from a University System of Georgia STEM II Initiative grant. We acknowledge members of the GGC STEM II Initiative for their assistance in attitudinal assessment and data collection. We also thank two anonymous reviewers for helpful comments regarding manuscript preparation.

\section{REFERENCES}

American Association for the Advancement of Science (2011). Vision and Change in Undergraduate Biology Education: A Call to Action, Washington DC.

Boyer Commission on Educating Undergraduates in the Research University (1998) Reinventing Undergraduate Education: A Blueprint for America's Research Universities, State University of New York, Stony Brook.

Brynhildsen J, Dahle LO, Fallsberg MB, Rundquist I, Hammer M (2002). Attitudes among students and teachers on vertical integration between clinical medicine and basic science within a problem-based undergraduate medical curriculum. Med Teach 24, 286-288.

Dahle LO, Brynhildsen J, Fallsberg MB, Rundquist I, Hammer M (2002). Pros and cons of vertical integration between clinical medicine and basic science within a problem-based undergraduate medical curriculum: examples and experiences from Linköping, Sweden. Med Teach 24, 280-285.

Derraik JGB, Early JW, Closs GP, Dickinson KJM (2009). Morphospecies and taxonomic species comparison for Hymenoptera. J Insect Sci 10, 108.

Folmer O, Black M, Hoeh W, Lutz R, Vrijenhoek R (1994). DNA primers for amplification of mitochondrial cytochrome c oxidase subunit I from diverse metazoan invertebrates. Mol Mar Biol Biotechnol 3, 294-299.

Foottit RG, Adler PH (2009). Insect Biodiversity: Science and Society, Chichester, UK: Wiley-Blackwell.
Healey M, Jenkins A (2009). Developing Undergraduate Research and Inquiry, York, UK: Higher Education Academy.

Hebert PDN, Cywinska A, Ball SL, deWaard JR (2003). Biological identifications through DNA barcodes. Proc R Soc Lond B Biol Sci 270, 313-321.

Kardash CM (2000). Evaluation of an undergraduate research experience: perceptions of undergraduate interns and their faculty mentors. J Educ Psychol 92, 191-201.

Karukstis KK, Elgren TE (eds.) (2007). Developing and Sustaining a Research-Supportive Curriculum: A Compendium of Successful Practices, Washington, DC: Council on Undergraduate Research.

Lopatto D (2004). Survey of Undergraduate Research Experiences (SURE): first findings. Cell Biol Educ 3, 270-277.

Lopatto D (2007). Undergraduate Research Experiences Support Science Career Decisions and Active Learning. CBE Life Sci Educ 6, 297-306.

Nangendo G, Stein A, Gelens M, de Gier A, Albricht R (2002). Quantifying differences in biodiversity between a tropical forest area and a grassland area subject to traditional burning. Forest Ecol Manag 164, 109-120.

Park D, Foottit R, Maw E, Hebert PDN (2011). Barcoding bugs: DNA-based identification of the true bugs (Insects: Hemiptera: Heteroptera). PLoS One 6, e18749.

Russell SH, Hancock MP, McCullough J (2007). Benefits of undergraduate research experiences. Science 316, 548-549.

Seymour E, Hunter AB, Laursen S, DeAntoni T (2004). Establishing the benefits of research experiences for undergraduates: first findings from a three-year study. Sci Educ 88, 493-594.

Shaffer CD, Alvarez C, Bailey C, Barnard D, Bhalla S, Chandrasekaran C, Chandrasekaran V, Chung H, Dorer DR, Du C, et al. (2010). The Genomics Education Partnership: successful integration of research into laboratory classes at a diverse group of undergraduate institutions. CBE Life Sci Educ 9, 55-69.

Triplehorn CA, Johnson NF (2005). Borror and Delong's Introduction to the Study of Insects 7th ed., Belmont, CA: Thomson Brooks/Cole.

Walsh PS, Metzger DA, Higuchi R (1991). Chelex 100 as a medium for simple extraction of DNA for PCR-based typing from forensic material. Biotechniques 10, 506-513.

Wei CA, Woodin T (2011). Undergraduate research experiences in biology: alternatives to the apprenticeship model. CBE Life Sci Educ 10, 123-131. 